\title{
Transformações na imprensa recifense em tempos de Gilberto Freyre: relações de gênero e processo de produção nos suplementos literários nos anos 1920
}

Tercio de Lima AMARAL ${ }^{1}$ Alcileide Cabral do NASCIMENTO ${ }^{2}$

Aline Maria Grego LINS $^{3}$

Resumo:

$\mathrm{O}$ artigo tem o objetivo de identificar como as mudanças sociais, culturais e econômicas em fins da Primeira República (1889-1930) foram inseridas nos suplementos literários recifenses. Esse é um período em que as elites letradas defenderam novas práticas de modernidade para o jornalismo de entretenimento, considerado um novo produto editorial produzido pela imprensa brasileira no início do século 20 . O pano de fundo para a análise são as relações de gênero flagradas nas edições dessas páginas especiais.

Palavras-chave:

Suplementos literários. Jornalismo cultural. Relações de gênero.

\section{Transformations in the Recife press in the times of Gilberto Freyre: gender relations and production process in literary supplements in the 1920s}

\begin{abstract}
:
The article aims to identify how the social, cultural and economic changes at the end of the First Republic (1889-1930) were inserted in the recifenses literary supplements. This is a period in which the literate elites defended new practices of modernity for entertainment journalism, considered a new editorial product produced by the Brazilian press in the beginning of the 20th century. The background for the analysis are the gender relations found in the editions of these special pages. Keywords:

Literary supplements; Entertainment journalism; Gender relations.

\section{Los cambios en los periódicos de Recife en los tiempos de Gilberto Freyre: relaciones de género y procesos de producción en los suplementos literarios en la década de 1920}

Resumen:

El artículo tiene como objetivo identificar cómo los cambios sociales, culturales y económicos al final de la Primera República (1889-1930) se insertaron en los suplementos literarios de Recife. Se trata de un

\footnotetext{
${ }^{1}$ Mestre em História da Cultura Regional (2016) pela Universidade Federal Rural de Pernambuco (URFPE), onde integra Núcleo de Pesquisas e Estudos em Gênero (Nupege). Doutorando em História no Programa de Pós-Graduação em História da Universidade Federal de Pernambuco (UFPE).

${ }^{2}$ Doutora em História pela Universidade Federal de Pernambuco (UFPE). Professora da Pós-Graduação em História da Cultura Regional da Universidade Federal Rural de Pernambuco (UFRPE), onde integra o Núcleo de Pesquisas e Estudos em Gênero (Nupege).

${ }^{3}$ Doutora em Comunicação e Semiótica pela Pontifícia Universidade Católica de São Paulo (PUC-SP). Professora do curso de Comunicação Social/Jornalismo da Universidade Católica de Pernambuco (Unicap) e Diretora Regional Nordeste da Sociedade Brasileira de Estudos Interdisciplinares da Comunicação (Intercom).
} 
período en que las élites letradas han defendido nuevas prácticas modernas para el periodismo de entretenimiento, considerado un nuevo producto editorial de la prensa brasileña a principios de siglo 20. El telón de fondo para el análisis de las relaciones de género son capturados en ediciones de estas páginas especiales.

Palabras clave:

Suplementos literários. Periodismo cultural. Las relaciones de género.

\section{INTRODUÇÃO}

Um dos objetivos do jornalismo na década de 1920 pretendia enterrar sua relação com o passado, ainda que carregasse consigo velhas práticas. Num texto de 11 de setembro de 1927, o Diario da Manhã do Recife afirmava que era preciso ser "moderno", vibrar com novas técnicas do jornalismo e partir para novos caminhos editoriais. O presente artigo pretende verificar como essas mudanças são registradas nos suplementos literários recifenses desse período, observando as influências que orientaram as edições no que diz respeito às relações de gênero, por meio dos rastros deixados pelo próprio fazer jornalístico.

Analisamos os suplementos literários dos jornais Diario de Pernambuco, entre junho de 1924 e 1925; e Diario da Manhã, entre abril de 1927 e 1928. Nesse recorte de um ano, observamos quais eram os critérios de edição adotados para tratar das relações de gênero, a partir das pistas nas escolhas de textos, títulos, artigos, contos e poesias. Aliás, do Diario de Pernambuco, chamamos atenção para o fato de o jornal, fundado em 1825 e ainda em circulação, ser considerado a publicação em língua portuguesa mais antiga em atividade no mundo. Outra observação importante é que nossa análise começa no momento em que os dois jornais publicam os seus primeiros suplementos literários na década de 1920, quando foram pioneiros nesse tipo de conteúdo. Porém, após o nosso recorte, essas publicações continuaram a manter, de forma regular, seus suplementos ao longo do século XX.

Buscamos observar de que forma se estabelecia a opção editorial sobre a temática das relações de gênero, constatando a predominância da visão masculina, uma vez que eram os homens, em sua maioria, os que ocupavam os cargos de colaboradores, redatores, secretários de redação e diretores. Recorremos, como fonte, à produção da historiografia sobre a imprensa recifense, a exemplo das obras dos jornalistas Luiz Nascimento (1967), Arnoldo Jambo (1975) e as memórias do sociólogo e jornalista Gilberto Freyre (2006). Este último, por exemplo, é responsável pelo "primeiro manual" de jornalismo da imprensa brasileira de que se tem notícia, elaborado quando Freyre foi 
convidado a dirigir o jornal recifense A Província, entre os anos de 1928 e 1930 (VIZEU, 2008).

A proposta do manual, nos anos de 1920, segundo Freyre, era demover os redatores do rebuscamento da escrita da época. Ele queria mais naturalidade, simplicidade na escrita. O que chama a atenção é que ele antecipou uma preocupação da imprensa brasileira que só surgiria na década de 1950, quando se tem registro dos manuais do Diário Carioca, do diretor Pompeu de Souza, e da Tribuna da Imprensa, de Carlos Lacerda, ambos na cidade do Rio de Janeiro (VIZEU, 2008).

Em seu livro de memórias, Tempos mortos e outros tempos, Gilberto Freyre relata que sua preocupação em lançar um "manual" era a de fazer de A Província "um jornal diferente dos outros e fiel à sua condição de jornal de província. Autêntico. Honesto [...] dar ao noticiário e às reportagens um novo sabor, um novo estilo: muita simplicidade de palavra, muita exatidão, algum pitoresco" (FREYRE, 2006, p. 248, 319).

A revelação do escritor aponta para nossa hipótese de que os aspectos editoriais adotados pelos jornais recifenses, no que se refere ao feminino e ao masculino, eram pensados como instrumentos de decisão editorial já na década de 1920. Ou seja, os títulos, as legendas, a localização dos textos e a escolha dos temas dos suplementos literários ganhavam importância para a definição do que deveria ser noticiado, diferente do que acontecia no jornalismo do século XIX. As técnicas de edição dos produtos jornalísticos e as páginas do jornalismo de entretenimento marcavam, portanto, terreno como instrumento pedagógico e também de opinião.

As ferramentas de edição, por meio de palavras e diagramação de páginas, revelariam os recursos opinativos dos autores de artigos e jornalistas sobre a mulher, o homem e as relações de gênero no período. A jornalista e historiadora Marialva Carlos Barbosa (2007) relata que algumas das premissas da profissão do jornalista e da reportagem foram fundamentadas ainda nos anos 1920. Segundo Barbosa, a mítica da vocação, do amor à profissão, dos sacrifícios, da necessidade de informar com isenção e longe das polêmicas políticas, formula um "lugar de fala" no mundo do jornalismo que ultrapassa os limites da década (BARBOSA, 2007, p. 83).

Na história da comunicação, são poucos os trabalhos que abordam a temática abordada por este artigo no período que compreende a Primeira República (1889-1930). Não só no que tange à história do processo de produção dos jornais, como também ao 
conteúdo sobre gêneros. Além de serem escassos os relatos de jornalistas recifenses sobre o tema, enfrentamos a velha dificuldade quanto às condições e ao acesso aos acervos públicos e dos jornais. Listas de funcionários, páginas diagramadas, atas sobre reuniões, por exemplo, não existem e/ou não foram preservadas em arquivos, pelo menos não no Recife.

Nos anos 1920, o editor pedia a cobertura cotidiana e os redatores de banca, que ficavam na redação e/ou faziam tradução de artigos e reportagens estrangeiras, tinham liberdade para tratar das temáticas sob a forma de artigos opinativos. Além desses profissionais, os jornais também tinham o secretário, que fazia a ligação entre a redação e o parque gráfico. Tal organização sofria algumas alterações em determinadas regiões do Brasil, mas com essa estrutura básica.

Para este artigo, recorremos aos relatos de Gilberto Freyre e às edições especiais de aniversário dos jornais Diario de Pernambuco, entre 1920 e 1929, e Diario da Manhã, entre 1927 e 1928, para entender parte desse processo. Nas edições comemorativas, há informações sobre rotativas, artigos de opinião e o registro de felicitações de autoridades, até dos concorrentes. Os exemplares do Diario de Pernambuco foram cedidos, digitalizados, a esta pesquisa pela D.A. Press, empresa dos Diários Associados, proprietária do jornal. Já do Diario da Manhã, os exemplares analisados foram disponibilizados pela Companhia Editora de Pernambuco (Cepe).

Com a leitura desses jornais, nossa intenção é destacar como a forte presença masculina nas redações influenciava as pautas e temáticas sobre a mulher e as relações de gênero nos suplementos recifenses. A edição estava nas mãos dos homens e o poder do que seria publicado também. O resultado dessa divisão desigual revela uma imprensa, por vezes, caricata, quando não preconceituosa, sobretudo em temáticas envolvendo o feminismo. Para a mulher, nesses jornais, quase sempre o casamento era a única esperança e caminho de (in)felicidade a seguir.

\section{No Diario de Pernambuco, "ser feliz é o mais difícil"}

Em uma de suas edições o suplemento Magasine, do Diario de Pernambuco, reproduz um manual elaborado pela atriz norte-americana Aileen Pringle, intitulado "Os dez mandamentos do amor". O texto, publicado em 13 de julho de 1924, narra 10 tópicos direcionados ao público feminino. Os "conselhos" são para as mulheres atenderem a contento os homens, parceiro ou marido. "Não sejas prodiga. Reserve 
sempre teus beijos para o homem com quem te casares. Aquela que a muitos beija não ama a nenhum", revela o primeiro mandamento. $\mathrm{O}$ texto segue impondo à mulher regras de como não olhar para outros homens, evitar perceber defeitos do marido, ser obediente e afetuosa, sem esquecer as responsabilidades do lar. Publicado em destaque, em espaço nobre, na parte superior da página do suplemento, o artigo revela o privilégio dado pela edição para um tema escrito por uma mulher. Que mais crível do que uma mulher, supostamente bem sucedida, aconselhar outras mulheres num mundo cercado de regras de comportamento?

Os mandamentos de Aileen Pringle destacam-se pela linguagem dirigida ao público "feminino", apesar de ser o homem, no final das contas, o centro das atenções do texto: “...não temas demonstrar teu carinho quando falares ao homem que amas. Mais de um afeto, desses que enchem e confortam uma existência, morrem ao nascer por causa de um mal entendido recato", complementa o quinto mandamento (PRINGLE, 13 jul. 1924 p. 7). Contudo, nem a autora acredita que seguir tais regras seja sinônimo de felicidade. É como se as mulheres tivessem como obrigação dar afeto, mas não receber nada em troca. No décimo mandamento, ela é curta e direta e pede a sua leitora: "Seja feliz (o que é mais difícil)". (PRINGLE, 13 jul. 1924, p. 7).

Apesar de o texto ser de uma mulher, refletia a forte tradição patriarcal da sociedade recifense (ou brasileira). Eram os jornalistas, homens em sua maioria, que editavam, escolhiam e ilustravam as matérias, artigos, poesias e contos dos suplementos literários recifenses da primeira metade do século XX. Era dos homens a tarefa de escrever sobre as mulheres ou, no mínimo, escolher quais mulheres poderiam escrever para os seus jornais. A participação feminina, nesse caso, acontecia fora do ambiente do jornalismo factual, tal como o texto de Pringle, ou os textos das escritoras Julia Lopes de Almeida e Edwiges de Sá Pereira.

Julia Lopes nasceu em 1862, no Rio de Janeiro. Filha de portugueses, ainda na juventude colaborou com $A$ Gazeta, de Campinas, em São Paulo. Teve a rara oportunidade de completar seus estudos na Europa, por influência do pai, o médico Valentim Lopes, conhecido como um "liberal". Em Portugal, lançou o livro Traços e iluminuras (SCHUMA, 2000, p. 305), coletânea de contos e poemas, publicados antes na imprensa. Ainda em 1890, escreveu para jornais de grande circulação, como o tradicional Jornal do Commercio, e para o feminino Jornal das Senhoras, ambos no Rio de Janeiro. 
Nos textos de autoria feminina a que tivemos acesso nos suplementos recifenses, observamos, de um modo geral, que para as mulheres restavam as temáticas relativas ao casamento, ao sofrimento e ao que denominamos hoje de "antifeminismo", ou seja, textos em que as próprias mulheres se posicionavam, às vezes, contra temas e direitos femininos, a exemplo do voto. Julia Lopes, apesar de falar também de casamento, quebrava essa regra ao repudiar a "supremacia masculina, a negação do direito ao voto às mulheres, a exploração no trabalho, à escravidão dos negros e as violências sexuais contra a mulher" (SCHUMA, 2000, p. 305).

O Diario de Pernambuco, a partir da segunda década do século 20, foi para o comando da família Lyra, composta por usineiros do vizinho estado de Alagoas, que contava com ramificações na política. O jornal foi adquirido pela família em janeiro de 1913 do então conselheiro Rosa e Silva. Ao comprar o jornal no Recife, a família Lyra implantou uma forma diferenciada na gestão. Uma das testemunhas dessa mudança foi o sociólogo Gilberto Freyre. A família comandou o jornal até o início dos anos 1930, quando o jornal passou para as mãos de um antigo repórter, o fundador e proprietário dos Diários Associados, Assis Chateaubriand Bandeira de Melo. Chateubriand começou a trabalhar no Diario de Pernambuco em 1909, aos 17 anos, e incorporou o Diario de Pernambuco aos Associados em junho de 1931 (MORAIS, 1994.

A primeira fase de colaboração de Gilberto Freyre no Diario foi de 1918 a 1928. A participação no jornal começou no exterior, enviando artigos durante sua formação no curso de Ciências Políticas, na Universidade de Columbia, nos Estados Unidos. Freyre relata, em sua autobiografia, as dificuldades no jornal nesse período, as suas relações com os donos da empresa e a tentativa dos colegas de imprensa em "imitar o seu estilo". Regras de pontuação, acentos e algumas passagens textuais - garantiu ele -, ficaram marcadas na imprensa recifense como sua "marca pessoal" (FREYRE, 2006, p. 248).

O jornalista fala também sobre as condições de trabalho dos profissionais da imprensa da época. Relata que parte do que recebia no Diario como colaborador, em torno de quinhentos mil-réis, ajudava na fonte de renda, mas não era a principal. Esse trabalho era considerado "humilhante" pelo escritor, que só conseguiria a consagração no mundo das letras nos anos 1930, com a publicação do livro Casa Grande \& Senzala.

Gilberto Freyre era um dos poucos jornalistas recebidos no andar residencial do Diario de Pernambuco, habitado por seu diretor, Carlos Lyra Filho. Na autobiografia, Freyre fala da personalidade do diretor. Segundo ele, Lyra Filho era viúvo, um homem 
discreto e sem "vaidades sociais". Apesar de ocupar o cargo de direção de um jornal importante no Recife, não circulava em eventos, nem recebia personalidades em sua casa. O reflexo do conteúdo publicado no suplemento Magasine, de certa forma, correspondia à personalidade do diretor: discreto, conservador, pouco aberto a conversas, a pessoas e a novas ideias.

Nesse contexto, identificamos a participação restrita de mulheres no jornal. A partir de relatos do período, podemos afirmar que algumas, assim como os homens, recebiam por seus artigos. Uma das colaboradoras do Magasine do Diario de Pernambuco, a escritora Julia Lopes de Almeida, como outras escritoras, confirma essa prática. Porém, não tinha a atividade da imprensa como a única fonte de renda. Esposa do poeta Felinto de Almeida, Júlia, de família tradicional, não dependia do que publicava no impresso. Assim como Gilberto Freyre e os homens que atuavam na imprensa, o exercício do jornalismo para as mulheres era uma forma de divulgar o nome no mundo letrado. A baixa remuneração na imprensa talvez fosse o único quesito que, ironicamente, homens e mulheres estavam em "pé de igualdade", exceto, claro, nos cargos da administração, como de diretores, que recebiam quantias maiores, redutos exclusivamente masculinos.

Dentro das práticas nas relações de gênero da imprensa brasileira, a remuneração, talvez, não fosse o principal interesse das mulheres. $O$ que chama a atenção na produção de Júlia Almeida é que, como poucas mulheres de sua época, ela tinha o jornalismo e a literatura como uma atividade e meio de expressão. Um dos seus livros, Contos Infantis, publicado em parceria com a irmã Adelina Lopes, chegou a ser aprovado por autoridades brasileiras e portuguesas para ser adotado em escolas primárias dos dois países. Em 1896, publicou O livro das noivas, um manual de preparação das mulheres para o casamento. Em 1922, a convite de Bertha Luz, participou da Comissão de Relações Internacionais e Paz do I Congresso Internacional Feminista promovido pela Federação Brasileira pelo Progresso Feminino. Júlia Almeida era considerada à época uma das mulheres de prestígio no meio cultural do país.

No Diario de Pernambuco, os textos publicados por Julia Almeida não faziam referência aos direitos e avanços femininos. Trabalhamos com a hipótese de que, no processo de escolha da edição, os editores dos artigos e textos do suplemento Magasine filtravam as produções femininas, para não dizer, censuravam, deixando de fora o que não se adequava ao padrão editorial do jornal, ainda que reconhecessem o valor literário 
e jornalístico de mulheres como Júlia. Tanto que publicavam os seus textos que não apresentavam a causa feminista. Assim, os suplementos recifenses publicavam artigos tímidos, conservadores.

Um exemplo desse cenário é a publicação do texto "O dia do casamento", veiculado na edição de $1^{\circ}$ de junho de 1924. Uma espécie de crônica de Júlia Lopes de Almeida, que recebeu destaque na página e que falava da expectativa de uma mulher antes de consumar a união. As porta-vozes e protagonistas da tensão familiar são duas personagens. A mãe que não pode conter a filha, obrigada a se despedir do lar, que é apresentada como uma noiva que até então não tem informações, experiência e, a partir do casamento, enfrentará uma nova realidade. Quais seriam essas "informações"? Nem o nome da noiva nem o da mãe são revelados no texto. Enquanto isso, o pai da família e o noivo estão tranquilos e encaram tudo com naturalidade. $\mathrm{O}$ casamento segue o roteiro de que a união matrimonial é a sublime "missão feminina" (ALMEIDA, 1. jun. 1924, p. 7). Nesse quesito, os homens, ao escreverem também sobre o casamento nos suplementos, acabavam adotando a mesma linha.

\section{Formas distintas na escrita de homens e mulheres}

Em nossa pesquisa, outra importante fonte foram as edições especiais de aniversário dos jornais Diario da Manhã e Diario de Pernambuco ao longo da década de 1920. No caso do Diario de Pernambuco, chama a atenção a publicação de um texto de mais de uma página, sendo uma delas inteira e sem anúncios, assinado por Edwiges de Sá Pereira. A publicação é datada de 7 de novembro de 1925, edição que comemorava o centenário do jornal.

O artigo, intitulado "A Mulher Pernambucana: sua influência e ação em nosso meio social, literário e artístico", abre espaço para uma escritora, em meio a dezenas de colaboradores masculinos, trazendo à tona um texto que defendia a inserção da mulher em episódios marcantes da história do Estado, enaltecendo a participação feminina nas lutas libertárias. No texto, Edwiges valoriza a participação de mulheres em episódios da história de Pernambuco que foram decisivos na formação do País. "Penso poder aduzir a este conceito esse outro: que a mulher brasileira da colônia tinha na pernambucana de então o seu melhor padrão, o seu tipo mais completo" (SÁ PEREIRA, 7 nov. 1925, p. 7). No artigo, a escritora nomeia "personagens guerreiras", como Dona Barbara de Alencar, colaboradora da Revolução de 1817; dona Clara Carvalhista, legionária da 
Revolução de 1824; e dona Anna Aurora de Jesus Ribeiro, da Revolução de 1848 (SÁ PEREIRA, 7 nov. 1925, p. 7). Ao contrário de outras escritoras do período, Edwiges dá nome e poder às suas personagens. Esse é um aspecto editorial raro no início do século $\mathrm{XX}$.

Edwiges de Sá Pereira nasceu em Barreiros, Pernambuco, em 1884. Filha do advogado José Bonifácio e de Maria Amélia de Sá Pereira, foi jornalista, poetisa e educadora. No final do século XIX e início do XX lutou pela emancipação feminina. Foi fundadora da Federação Pernambucana pelo Progresso Feminino (FPPF), uma filial da Federação Brasileira para o Progresso Feminino, na década de 1930. Ela foi a primeira mulher a tornar-se imortal na Academia Pernambucana de Letras. Seu discurso era apaziguador (NASCIMENTO, A. C., 2012, p. 7).

A organização dessa edição especial do Diario de Pernambuco ficou a cargo de Gilberto Freyre, que logo depois foi escolhido pelo próprio Carlos Lyra Filho para a direção geral do jornal. Deduz-se, assim, que a opção em publicar o artigo de Edwiges de Sá Pereira foi de Freyre. Na mesma edição especial, colaboraram nomes como Oliveira Lima, Samuel Hardman, Odilon Nestor, Aníbal Fernandes, Luís Cedro e Manuel Bandeira. O caderno especial foi considerado "primoroso" pelo próprio Freyre, que ficaria à frente do Diario de Pernambuco até 1928, quando deixa o jornal para assumir a chefia de redação do concorrente A Província (FREYRE, 2006, p. 236).

Mas, ainda no Diario, o sociólogo começa a abordar temas de seu interesse pessoal, inclusive no suplemento Magasine. Entre eles, temas como "senhoras e costumes ingleses", que eram uma verdadeira fascinação do autor de Casa Grande \& Senzala, e frequentes na publicação do jornal. Uma dessas abordagens é o artigo publicado em 10 de agosto de 1924, intitulado "Mulheres inventoras".

O texto narra a história de inventoras na Inglaterra, país pioneiro na Revolução Industrial. Publicado na margem inferior do suplemento, como uma curiosidade, o espaço destinado ao texto permite levantar a hipótese de que no Magasine, ao contrário do que parecia, não havia lugar para destacar os avanços femininos, como as patentes que as mulheres inglesas estariam conquistando com suas invenções, uma vez que esses feitos apareciam tão somente como curiosidades.

Nessa edição e, claro, sendo uma escolha masculina do tema para o jornal, nenhuma inventora é apresentada por seu nome. Elas são mencionadas no plural e sem categorização. É como se as inventoras inglesas existissem e não existissem ao mesmo 
tempo, sem nomeação, tratadas no plural, não tendo a mesma força, ainda que seus feitos fossem "importantes".

[...] cinco irmãs obtiveram patente por 'uma novidade em chapéus de senhoras e meninas', enquanto que outras inventoras tiravam patentes por invenção de peles laváveis, guarnições para cães e para outros animais domésticos, aparelhos para matar aves sem fazê-las sofrer, etc. Outras senhoras inventaram novos sistemas de caçarolas, de funis, de tinteiros de porta-penas e vários objetos de escritório.(...) $\mathrm{O}$ amor conjugal aparece, também, nos inventos femininos da Inglaterra. Muitas senhoras têm obtido patentes por sistemas novos e práticos de enfeitiçar. (MULHERES..., 10 ago. 1924, p. 7).

Além de não identificar as inventoras, informação de reconhecimento para as mulheres, o suplemento ironiza e até descredencia o feito feminino, ao citar que o amor conjugal também estaria entre as "invenções" e que as senhoras estavam conquistando patentes por "enfeitiçar" os homens.

É importante assinalar, contudo, que as mulheres, apesar de em menor número, também eram produtoras de notícias nos anos 20 e apresentavam sua visão de mundo pela imprensa, em outros jornais da capital pernambucana que não foram objeto desta pesquisa. Ou seja, existiram outras formas de representação além dos suplementos. Esse foi o caso da escritora e jornalista Alice Pimenta, que escreveu no jornal recifense $O$ Tacape, publicado entre os anos de 1928 e 1930. Alice Pimenta defendia temas como o divórcio e o comunismo. Ela era casada com o então deputado pernambucano Joaquim Pimenta (REZENDE, 1987, p. 141) e tinha destaque na sociedade recifense, tanto que o escritor José Lins do Rêgo, em seu primeiro romance urbano, O moleque Ricardo, teria transformado a escritora em uma de suas personagens. Observamos, no entanto, que pelo fato de $O$ Tacape não estar entre os grandes jornais da capital, apesar de ter durado mais de um ano e ter anunciantes, não conseguiu ter a mesma repercussão como tiveram os dois jornais focos do presente artigo.

\section{As "jornalistas" do Diario da Manhã querem a "higienização dos costumes"}

Letícia era escritora, talvez jornalista - mesmo que esse termo, na época, não fosse comum para definir as mulheres que escreviam em jornais. Sua aparição no jornal Diario da Manhã se dá numa época bastante especial para os fiéis da Igreja Católica: a Quaresma, período litúrgico que antecede a comemoração da Páscoa. Seu artigo 
intitulado "As mulheres e a religião" tem uma ressalva logo após a publicação do título. Os editores advertem: escrito por uma "pena feminina". No suplemento literário, a Bíblia e algumas passagens do texto cristão são citadas e demonstram que quem escreve domina o tema. Letícia, que não tem seu sobrenome revelado, no entanto, tem outro objetivo: combater "um olhar de comiseração para os escândalos procedentes da moda atual" e pede para que seus leitores sejam "fortes em repelir as suas imposições indecentes". Até porque, na visão dela, "o mundo parece retroceder à época do paganismo".

Ao publicar o artigo em 8 de abril de 1928, o Diario da Manhã reforça a estratégia editorial, adotada também pelo concorrente Diario de Pernambuco, em destacar textos publicados por mulheres que debatiam temáticas, na visão desses jornais, meramente femininas. Afinal, não eram os homens que estavam escrevendo ou "atacando" as mulheres. Elas mesmas defendiam suas bandeiras ou podiam reforçar a visão machista e misógina da época. Letícia, ao destrinchar seus conhecimentos religiosos, pede uma reação conservadora das mulheres cristãs às mudanças na sociedade no final dos anos 1920. "Zelemos a nossa dignidade de mulher cristã, cooperando assim para a higienização dos costumes - para a moralização das famílias e da sociedade" (LETÍCIA, 8 abr. 1928, p. 3) A autora é implacável ao falar dos braços que se exibiam nus, os ombros e os decotes que faziam corar as pessoas de pudor, as saias curtas "vergonhosamente subindo acima dos joelhos" (LETÍCIA, 8 abr. 1928, p. 3), além dos trejeitos de afetação no andar, que, para ela, eram a materialização da imoralidade sob a máscara da elegância.

A defesa da "higienização" dos costumes fez parte da realidade recifense e brasileira na Primeira República (1889-1930). Letícia não estava sozinha, o fato de seu trabalho ser selecionado no jornal, por editores homens, evidencia que o tema era de interesse da editoria do suplemento. Essa temática dialogava com os debates de seu tempo. A historiadora Susan Besse destaca que no período que abrange os anos de 1910 a 1940, havia entre os intelectuais brasileiros um consenso no qual o triunfo da "civilização" e do progresso estaria na salvação da família tradicional (BESSE, 1999, p. 63). E essas transformações estavam em todas as esferas. Era preciso avançar com a modernidade, mas conter novas demandas sociais, principalmente ligadas às mulheres.

A capital pernambucana, assim como a capital brasileira, no início do século 20 passava por mudanças na estrutura urbana. No Brasil, essa revolução urbana foi iniciada 
no Rio de Janeiro pelo então prefeito Pereira Passos, gestor da cidade de 1902 a 1906. Nessa época, também, foi inserida a cultura do sanitarismo no país, com médicos como Oswaldo Cruz. O Poder Público atuava para modernizar os espaços urbanos e promover a melhoria da saúde da população, principalmente a mais carente, mas que sofria com a perseguição estatal e a transferência de seus domicílios para locais mais afastados da cidade (LUBAMBO, 1991). Esse quadro repetiu-se no Recife com a reforma e reestruturação do porto da cidade e de seu bairro mais antigo, o Bairro do Recife.

A alteração do espaço urbano na capital pernambucana, contudo, foi abraçada por diversas correntes. Oposição e governo defendiam os mesmos valores quando o assunto era a "modernização" da capital. As mudanças no bairro começaram na gestão de governadores ligados ao conselheiro Rosa e Silva, mas continuaram em gestões posteriores. Em 1911, o general Dantas Barreto assume o governo de Pernambuco e o plano de reforma do porto e do Bairro do Recife continua a todo vapor (LUBAMBO, 1991).

No campo cultural, a Escola do Recife, nascida em 1870, cujos valores influenciaram nomes como Gilberto Freyre, passou, por sua vez, a defender um "modernismo" com "tradições regionais". O historiador Flávio Weinstein Teixeira reforça que as mudanças urbanas e culturais refletiram-se no comportamento. Essa renovação cultural passou a operar na década de 1920 uma dupla função: refundação da identidade nacional e reposicionamento da produção cultural, como forma de expressão (TEIXEIRA, 2014, p. 125). O Recife, nesse período, vivia um bom momento na produção literária, com o nascimento do movimento regionalista, em 1926, liderado por Gilberto Freyre, que defendia valores locais como elemento formador da identidade nacional. É bom assinalar que o Modernismo brasileiro teve seu marco inicial na Semana de Arte Moderna, em São Paulo, entre 11 e 18 de fevereiro de 1922. O crítico literário Alfredo Bosi argumenta que, ainda com a resistência do sociólogo Gilberto Freyre e do escritor José Lins do Rêgo, houve contato de escritores de Pernambuco com o grupo de São Paulo, entre eles, o jornalista Joaquim Inojosa, do Jornal do Commercio, do Recife, e o escritor Guilherme de Almeida (BOSI, 2006, p. 343).

O Diario da Manhã também absorveu esse espírito, afinal, o jornal estava localizado no bairro de Santo Antônio, vizinho ao Bairro do Recife, em transformação. Sua diagramação "moderna", as mudanças técnicas que se inserem na imprensa recifense com seu protagonismo no mercado de comunicação também são um reflexo 
dessas alterações. No período de nossa análise, o jornal era dirigido exclusivamente por homens. O redator-chefe era José de Sá, o redator-secretário, Cristiano Cordeiro, e entre os redatores principais estavam Esmaragdo de Freitas, Racine Guimarães, Domício Borba. Infelizmente, ao contrário do Diario de Pernambuco, não temos relatos do cotidiano da redação do Diario da Manhã, mas é interessante notar que o jornal também gozava de uma "tradição familiar".

Do mesmo modo que Carlos Lyra Filho estava à frente do patrimônio familiar do Diario de Pernambuco, os irmãos Carlos, Caio, Artur e Fernando de Lima Cavalcanti administravam o Diario da Manhã. A direção geral era de Carlos Lima Cavalcanti e o seu irmão Caio era o diretor-substituto. As informações sobre o quadro de colaboradores do jornal no final da década de 1920 são registradas pelo jornalista Luiz do Nascimento (1967), que pesquisou sobre a história da imprensa recifense na primeira metade do século 20, mas não se debruçou sobre a questão das relações de gênero.

Vale salientar, porém, que a partir do acervo dos suplementos literários, foi possível identificar que homens e mulheres que atuavam na imprensa local se posicionavam sobre essa questão, em especial por meio do jornalismo literário. Entre os assuntos mais debatidos pelo Diario da Manhã, por exemplo, estavam o divórcio, o adultério e o voto feminino. De um modo geral, os editores e colaboradores do jornal apresentavam visões bem conservadoras, mas não era regra.

Sobre o adultério feminino, o jornal tinha uma forma "particular" de julgá-lo como impróprio. Por meio de artigos e contos literários, o Diario da Manhã advertia os/as leitores/as sobre as implicações sociais para a mulher que cometia traição ao marido. Um dos exemplos é a publicação do conto "A mulher adúltera", presente na edição de 27 de novembro de 1927. O texto, assinado por G. C. Cesario, adverte os/as leitores/as que se trata de uma publicação estrangeira, com "tradução especial" para o impresso pernambucano. O conto traz a história de uma mulher de nome Ercilia, que não tem o sobrenome revelado, e que pede autorização a um padre para cometer o "pecado". Na verdade, o marido estava internado há anos em um manicômio e não tinha nenhuma perspectiva de melhoras no quadro de loucura. Ela, portanto, era casada oficialmente, mas não gozava da companhia do marido e não poderia contar com ele no futuro.

Ercilia confessa ao padre que já teria beijado um novo pretendente. Fala que está com cerca de 30 anos e não poderia jogar sua vida fora em nome de um relacionamento 
que não tem mais futuro. Sua intenção era pedir ao padre a "autorização" para consumar uma possível relação mais íntima. Ela argumenta que a sociedade é hipócrita, e diz que o "amante" é um militar respeitado e viúvo, que tem uma filha pequena e que pode ficar doente caso não prossigam com o relacionamento. $\mathrm{O}$ texto é também marcado pelas contestações do padre: “- A lei de Deus é terminante, minha filha...”, diz o padre, cuja resposta recebe imediatamente: “- Bem sei. Ella também diz: 'Não matarás'. O senhor, entretanto, como os demais capelães de regimento, não fazia senão pregar aos soldados a guerra de extermínio, a luta sem tréguas" (CESARIO, 27 nov. 1927, p. 3). Ercilia não obtém a autorização. Para justificar as contradições apontadas por Ercilia, o religioso diz que a mulher tem o vício do paradoxo. O religioso pede para que ela escreva um telegrama rompendo com o relacionamento e reze para Santa Madalena, mas o texto dá a entender que o romance persistiu.

O tema do adultério era caro à edição do jornal. Para se ter uma ideia, o conto conquistou as oito colunas na diagramação do Diario da Manhã, que preencheu toda a página do suplemento literário com a história dramática, envolvendo religião e moral. Sem dúvida, um tema de interesse dos editores e, claro, do público.

A historiadora Susan Besse (1999, p. 50) afirma que o adultério feminino se tornou uma obsessão entre os intelectuais na década de 1920. Isso reforça a nossa hipótese de que os suplementos literários, ao editarem e produzirem contos como o de Ercilia, não se portavam imparcialmente, afinal, o tratamento dado ao texto não era o mesmo quando o adultério era masculino, visto como diferentes nos dois gêneros. Os críticos, que estavam presentes nos jornais, também protestavam contra o fato de as "virgens" e as "esposas" estarem aprendendo com o cinema e o teatro a arte de "atraiçoar” o possível marido.

\section{Considerações finais}

Os jornais Diario de Pernambuco e Diario da Manhã fizeram parte de uma nova realidade do jornalismo brasileiro que começou no Rio de Janeiro, em fins do século 19, e em Pernambuco, mais precisamente, no início do século XX (BARBOSA, 2010, p. 117). As duas publicações são frutos do começo da profissionalização do jornal como produto industrial. Esse foi o momento em que a circulação, a tiragem, os aspectos gráficos e linguísticos ganhavam mais importância para os produtores de conteúdo. Tanto é que, para atrair novos/as leitores/as e manter os literatos que gozavam de uma 
parceria desde o século XIX, os jornais começaram a publicar os suplementos literários em suas edições. Os suplementos, neste sentido, se transformaram em um dos primeiros produtos de consumo do jornalismo cultural brasileiro. Sua publicação fez parte da "modernização" da imprensa e da sociedade, termo tão valorizado na época.

Com homens dirigindo essas empresas jornalísticas, tanto na questão administrativa como na redação, a exemplo da gestão de Carlos Lyra Filho e de Gilberto Freyre no Diario, as mulheres se tornaram alvos fáceis de suas discussões. Sob o olhar da imprensa dos suplementos, a mulher era uma espécie de objeto masculino. Objeto não no sentido apenas sexual, mas editorial e analítico. Esse jornalismo cultural do período estava preocupado de forma excessiva com o gênero feminino. Isso ficou evidenciado do ponto de vista da produção dos textos, na análise dos artigos, contos e poesias, além das imagens. As mulheres estavam no centro da discussão de um mundo que estava se transformando. As mudanças, no entanto, precisavam ser "controladas" e seu embate era na imprensa, cuja leitura era praticada por homens e mulheres. Ao ler determinadas informações, as mulheres poderiam ser instruídas a respeito dos "riscos" que as alterações na vida do mundo moderno representavam para si e suas respectivas famílias.

A concepção gráfica do jornal, suas novas sedes e a maior frequência no uso de agências internacionais de notícia não mudaram o quadro e a forma de conceber a vida em sociedade nas páginas dessas publicações tradicionais. No século XIX, ou seja, num período anterior, as mulheres mantinham a mesma forma e a temática na maioria de suas poesias e escrita. O jeito "doce", a forma "amena" de reivindicar direitos ou de demonstrar sofrimento permaneceram como herança do Império do Brasil (1822-1889) para meados da Primeira República (1889-1930) nesses suplementos. Para isso, mesmo com a virada do século, os jornalistas e editores desses suplementos utilizavam, ironicamente, técnicas "modernas" naquele tempo para manter os velhos padrões de pensamento. Era um diálogo do novo com o velho na resistência às mudanças. Nossa intenção é contribuir para o debate da igualdade de gênero, do ponto de vista histórico, e chamar a atenção para práticas atuais sobre essa temática ainda vigente nas redações do país.

Submetido em 06.04.2016

Aceito em 03.09.2016 


\section{REFERÊNCIA BIBLIOGRÁFICA}

BARBOSA, Marialva Carlos. História cultural da imprensa: Brasil, 1900-2000. Rio de Janeiro: Mauad, 2007. 2010.

.. História cultural da imprensa: Brasil: 1800-1900. Rio de Janeiro: Mauad,

BESSE, Susan K.. Modernizando a desigualdade: reestruturação da ideologia de gênero no Brasil, 1914-1940. São Paulo: Editora da Universidade de São Paulo, 1999.

BOSI, Alfredo. História concisa da literatura brasileira. São Paulo: Cultrix, 2006.

FREYRE, Gilberto. Tempo morto e outros tempos: trechos de um diário de adolescência e primeira mocidade (1915-1930). São Paulo: Global, 2006.

JAMBO, Arnoldo. Diário de Pernambuco: história e jornal de quinze décadas. Rio de Janeiro: Empresa Gráfica O Cruzeiro, 1975.

LUBAMBO, Cátia Wanderley. O bairro do Recife: entre o Corpo Santo e Marco Zero. Recife: Cepe/Fundação de Cultura da Cidade do Recife, 1991.

MORAIS, Fernando. Chatô, o rei do Brasil: a vida de Assis Chateaubriand. São Paulo: Companhia das Letras, 1994.

NASCIMENTO, Alcileide Cabral do. Por uma igualdade emancipadora da mulher: Edwiges Sá Pereira e Martha de Holanda, feministas em luta pela cidadania política em Pernambuco dos anos 30. ENCONTRO REGIONAL DE HISTÓRIA DA ANPUH-RIO, 15., Rio de Janeiro, 2012.

NASCIMENTO, Luiz do. História da imprensa de Pernambuco (v. III). Recife: Imprensa Universitária, 1967.

REZENDE, Antônio Paulo. A questão da autonomia e a classe trabalhadora (1921/1922). In: REZENDE, Antônio Paulo (Org.). Recife: que história é essa? Recife: Fundação de Cultura Cidade do Recife, 1987.

SCHUMA, Schmader; BRASIL, Érico Vidal. Dicionário mulheres do Brasil: de 1500 até a atualidade. Rio de Janeiro: Jorge Zahar, 2000.

VIZEU, Alfredo. Gilberto Freyre e os manuais de redação. Comunicação \& Sociedade. São Bernardo do Campo, Pós Com-Metodista, ano 29, n. 50, p. 163-177, 2 sem. 2008. Disponível em: $\quad<$ https://www.metodista.br/revistas/revistasims/index.php/CSO/article/viewFile/714/715>. Acesso em: 25 mar. 2016.

TEIXEIRA, Flávio Weinstein. Recife: notas em torno da gênese de um campo cultural. Clio, Revista de Pesquisa Histórica. Série História do Nordeste (UFPE), Recife, v. 32.2, p. 117-143, 2014. Disponível em: $<$ http://www.revista.ufpe.br/revistaclio/index.php/revista/article/viewFile/435/233>. 


\section{Periódicos e documentos}

ALMEIDA, Julia Lopes de. O dia do casamento. Diario de Pernambuco, Recife, $1^{\circ}$ jun. 1924. Suplemento Magasine, p. 7.

CESÁRIO, G. C. A mulher adúltera. Diario da Manhã, Recife, 27 nov. 1927. Literatura, p. 3.

LETÍCIA. As mulheres e a religião. Diario da Manhã, Recife, 8 abr. 1928. Suplemento Literatura, p. 3.

MULHERES inventoras. Diario de Pernambuco, Recife, 01 ago. 1924. Suplemento Magasine, p. 7.

PRINGLE. Aileen. Os dez mandamentos do amor. Diario de Pernambuco, Recife, 13 jul. 1924. Suplemento Magasine, p.7.

SÁ PEREIRA, Edwiges de. A mulher pernambucana: sua influência e ação em nosso meio social, literário e artístico. Diario de Pernambuco, Recife, p. 7, 7 nov. 1925. 